\title{
Study on the Inter - ethnic Political Integration in Urban National Autonomy of Henan Province in the Early Days of New China
}

\author{
Lingchong Jia \\ Zhengzhou University of Industrial Technology, Xinzheng, Henan, 451100
}

Keywords: Kaifeng Hui, Urban National Autonomous Region, Inter-Ethnic Political Integration.

\begin{abstract}
Henan Province established three urban national autonomous regions. Taking Kaifeng Hui Autonomous Region as an example, the operation history is interpreted at the political level. The main policy is embodied as "sympathy" and "autonomy". The result of the operation is the effective integration of inter-ethnic politics, and in this way, China's Ideal New Ethnic Relations.
\end{abstract}

\section{Introduction}

It is not advisable to fully copy the pattern of ghetto in a distinctive area. For the blind experience of foreign experience, mechanical addition, inevitably lead to rejection of the results. And "in-depth understanding of the case and systematic analysis, from the case and classification studies, rose to the regularity of the overall premise of knowledge." [13] Therefore, the theory of urban national work in Henan Province, we must re-examine the origin of its historical coordinates, according to the case into the connotation of local experience in order to obtain a solid argument to support. And 1953 was established in the capital of Henan Province, Kaifeng City Hui Autonomous Region, in the sense of the sample is undoubtedly a clear advantage.

\section{The construction of Kaifeng Hui before and after the basic situation}

Kaifeng Hui history can be traced back to the early Tang and Song Dynasties, in 1953 when there are 10855 people, accounting for $6.2 \%$ of the total population of the city, accounting for 93.09\% of ethnic minorities. At that time, the "People's Republic of China regional autonomy implementation of the Outline" and "on the protection of all diasporas minority ethnic groups enjoy the right to equal rights of the people" was promulgated in August 1952. However, due to the incitement of enemy personnel, the end of 1952 to early 1953, Henan Hui Han ethnic relations are very tense, almost lead to riots, known as the "East event." The above "big background" and "microclimate" directly contributed to the implementation of the "autonomy" and "condolences" policies.

"East event" caused the central and Zhongnan Bureau of great importance. At the beginning of 1953, the South-South national delegation headed by the Secretary-General of the Central South Bureau arrived in Kaifeng, widely and in-depth propaganda policy, listen to the views of the Hui people, "rumors, running, sincerely praise." The delegation suggested that "ethnic regional autonomy should be implemented in the Muslim area," Mao Zedong made a long note on the report, namely the famous "criticism of the Han nationality." In March and May of the same year, Henan Province and the continuous organization of two provincial leaders led the national mission to the east. This series of high-standard, large-scale condolences, opened a new situation in Henan national work. In 1953 March, Kaifeng City convened Han, Hui, Man and other representatives of more than 40 people, "consultation to build the national autonomous region of the specific issues." [2] 81 followed by the organization of cadres to learn national policy, investigate and understand the situation, and through the residents group and other forms of extensive publicity, won the 
understanding and support of all ethnic groups. May 21, Kaifeng Hui Autonomous Region declared to be established.

From 1953 to 1956, the "sympathy" and "autonomy" in the urban national work of Henan Province were regarded as "inter-ethnic political integration", and the new state power was carried out on the original inter-ethnic political integration A complete transformation, to build a new set of inter-ethnic political integration "[3], and in this way effectively constructed the new Chinese ideal new ethnic relations.

\section{Through the condolences and autonomy, the new regime has successfully completed the construction and consolidation of the legitimacy of the ethnic minorities}

"Inter-ethnic integration within the multi-ethnic state to achieve, in the final analysis depends on the multi-ethnic countries and their governments in the national interests of the national interests of the fairness and legitimacy of the resulting." [1] 362 At that time, the urban work of the city in Henan could be regarded as the new regime through the transformation measures to achieve political and social double change, and then establish its political legitimacy process extension and expansion. The central government believes that "this visit to visit Henan, received a very good effect, a great political impact." [4] 127 Kaifeng Hui "after the establishment of the autonomous region, back to the Han ethnic relations appeared on a new unity of the weather" (1), ethnic integration greatly strengthened.

The local practice of Kaifeng should also be placed in a larger narrative background: the mobilization of the masses and the widespread absorption of ethnic minority activists into the party organizations at that time, effectively established the party beyond the specific ethnic groups, especially the Han as entire

\section{The entire ethnic policy system is extremely clear through the interests of the minority interests of the value orientation}

The essence of national policy is "the external manifestation of the value orientation of policy subject". It can be said that the difference of national policy is the difference of value orientation of national policy. [5] 74 In the value orientation, the national policy of the Kuomintang and the Communist Party is not so much the "difference" as the "difference" of the policy. Because the nation "provides its members with at least the continuation of the unique economic life, the inheritance of common culture and the prospect of the other three groups that are difficult to provide with the sharing of political power." [1] 357 Ethnicity is the presence of the scene, in the political operation level with the instrumental. In the period of the Republic of China, it was found that "the Muslims in Henan were also non-Hui," [6] 63 thus stifling the rights and interests of the Hui people by depriving them of political participation. While the CCP has adopted a policy of "national harmony" that attaches importance to the interests of ethnic minorities, and even "at the expense of certain local and temporary interests of the nation". [5] 73

The establishment of the new regime, so that the Chinese Communist Party on the nation's theory and program implementation, with a solid and material basis and political security. During this period the party's national work from theory to practice are extremely sincere, and access to legitimacy is only a secondary value orientation. Thus, although the concrete work carried out by the Kaifeng local regime inevitably had some deficiencies under the ideology of a strong idealism, the whole did not affect the enthusiasm of the ethnic minorities as a whole, and their influence on the leaders, the party and the government Into a strong trust and even worship (3), to promote the political power of the new regime and reputation quickly reached an unprecedented historical height. 


\section{The recognition of ethnic minorities' stratification, and with the united front, etc. to complete the political integration of the upper ethnic minorities}

The central soberly see the existence of stratification within the ethnic minorities, and the upper part of the masses in the people have a certain prestige and influence, put forward both to educate and organize the working people of ethnic minorities, but also on its upper elements of united front work. (4) for those who can fight for no fight, and strive for; can be united and united, all united. There are three main ways to integrate the upper echelons of Kaifeng: First, the ruling way, such as the autonomous regional government vice chairman and other four major leaders are Hui; the second is to participate in the way, mainly to select the national upper level into the NPC, CPPCC and other representatives of public opinion; Third is the united front way, mainly minority capitalists, landlords and religious superiors. Three ways corresponding to the three groups, from the power of the core from near and far, convergence as a whole.

Kaifeng as the capital of Henan Province, ethnic and religious figures gathered at the time, when the construction of such a unified object of more than 300 people. (5) Kaifeng Hui Muslims practiced a single system, the right to teach loose. In the Reformation, Kaifeng Islam was chaired by celebrity Ma Yunwu. "According to historical experience, respect and support of the Islamic minority representatives of the minority, for the proper handling of Islam, to promote the progress of Muslim society will play an important role." [7] 477 on the political integration of ethnic minorities, which is also a major highlight of the work of Kaifeng, its experience in today there is still practical significance.

\section{Acknowledgements}

Fund Project: 2018 Annual Henan Provincial Department of Education Humanities and Social Sciences Research Project" A Study on the Status and Function of Urban National District in Henan Province “(2018-ZZJH-582); 2017 Annual Zhengzhou University of Industrial Technology School-level key scientific research projects" A Study on the Status and Function of the Urban National District in the Central Plains “(2017ZD006).

\section{Commentaries}

(1)The imam said that "Hui and Han dynasty is like a brother", and "a lot of cooperation and mutual help" occurred in the production. See Kaifeng archives: report on the implementation of ethnic policy implementation in Kaifeng (1953), general no. 4, directory no. 1, volume: 1.

(2)In 1951, there were 14 members of the Hui ethnic group and 178 in 1953. Same as above. The glorious image of the vanguard of the Chinese nation. In terms of ethnic minorities in Henan, in the early days after foundation of politics, economy, culture and so on a series of New Deal, is establishing the image of the communist party of China "the vanguard of the Chinese nation" the key link, the previous similar movement, and then on the effect of depth, breadth and cannot be compared with the period.

(3)The minority people showed "the sincere affection and support of Chairman Mao, the communist party and the central people's government, the love of the motherland, the trust of the Han people, and the confidence in the construction of the motherland". The central united front research office: the general situation and literature of the national unified war work conference (1949-1988), Beijing: archive press, 1988 edition, 167-168, and 184 pages.

(4)The central literature research room: an anthology of important literature since the founding of the People's Republic of China (volume 4), Beijing: central literature publishing house, 1993 edition, p. 316.

(5)In 1954, a total of 313 ethnic minorities and Islamic United Nations were in Kaifeng. Kaifeng 
archives: the work of the communist party of China's Kaifeng municipal committee of the communist party of China (1955), the whole number: 4, directory number: 1 , case no. 1.

\section{References}

[1] Wang Jian'e, Chen Jianyue. Inter-ethnic politics and modern nation-state [M]. Beijing: Social Science Literature Publishing House, 2004.

[2] Zhao Jiazhen. Kaifeng National Religion [M]. Hong Kong: Tianma Publishing House, 2000.

[3] Zhou Ping. Research on the Inter-regional Political Integration Model in China [J]. Xinhua Abstracts, 2005,246 (22): 8-10.

[4] Central Literature Research Office. Mao Zedong's Contribution since the founding of the People's Republic of China (Volume 4) [M]. Beijing: Central Literature Publishing House, 1990.

[5] Zhou Ping. Introduction to national politics [M]. Beijing: China Social Science Press, 2001.

[6] Lin Chuanjia. Greater China Henan Geography [M]. Beijing: China Printing Office, 1920.

[7] Yu Zhengui. China's political power and Islam [M]. Yinchuan: Ningxia People's Publishing House, 1996. 